\title{
Benchmarking DNA Extraction Methods for Phylogenomic Analysis of Sub-Antarctic Rhodococcus and Williamsia Species
}

\author{
Akhikun Nahar ${ }^{1, *}$, Anthony L. Baker ${ }^{1}$, David S. Nichols ${ }^{2} \mathbb{D}$, John P. Bowman ${ }^{1}$ and Margaret L. Britz ${ }^{1, *} \mathbb{D}$ \\ 1 Tasmanian Institute of Agriculture, University of Tasmania, Hobart, TAS 7005, Australia; \\ Anthony.baker@outlook.com.au (A.L.B.); john.bowman@utas.edu.au (J.P.B.) \\ 2 Central Science Laboratory, Division of Research, University of Tasmania, Hobart, TAS 7005, Australia; \\ d.nichols@utas.edu.au \\ * Correspondence: Akhikun.nahar@utas.edu.au (A.N.); Margaret.britz@utas.edu.au (M.L.B.)
}

Citation: Nahar, A.; Baker, A.L.;

Nichols, D.S.; Bowman, J.P.;

Britz, M.L. Benchmarking DNA

Extraction Methods for Phylogenomic Analysis of Sub-Antarctic Rhodococcus and Williamsia Species. Microorganisms 2021, 9, 1253. https://doi.org/

$10.3390 /$ microorganisms 9061253

Academic Editor: Joel B. Dacks

Received: 21 April 2021

Accepted: 4 June 2021

Published: 9 June 2021

Publisher's Note: MDPI stays neutral with regard to jurisdictional claims in published maps and institutional affiliations.

Copyright: (C) 2021 by the authors. Licensee MDPI, Basel, Switzerland. This article is an open access article distributed under the terms and conditions of the Creative Commons Attribution (CC BY) license (https:/ / creativecommons.org/licenses/by/ $4.0 /)$.

\begin{abstract}
Bacteria containing mycolic acids in their cell envelope are often recalcitrant to cell lysis, so extracting DNA of sufficient quality for third-generation sequencing and high-fidelity genome assembly requires optimization, even when using commercial kits with protocols for hard-to-lyse bacteria. We benchmarked three spin-column-based kits against a classical DNA extraction method employing lysozyme, proteinase K and SDS for six lysozyme-resistant, sub-Antarctic strains of Corynebaceriales. Prior cultivation in broths containing glycine at highly growth-inhibitory concentrations (4.0-4.5\%) improved cell lysis using both classical and kit methods. The classical method produced DNA with average fragment sizes of 27-59 Kbp and tight fragment size ranges, meeting quality standards for genome sequencing, assembly and phylogenomic analyses. By 16S rRNA gene sequencing, we classified two strains as Williamsia and four strains as Rhodococcus species. Pairwise comparison of average nucleotide identity (ANI) and alignment fraction (AF), plus genome clustering analysis, confirmed Rhodococcus sp. 1163 and 1168 and Williamsia sp. 1135 and 1138 as novel species. Phylogenetic, lipidomic and biochemical analyses classified psychrotrophic strains 1139 and 1159 as $R$. qingshengii and R. erythropolis, respectively, using ANI similarity of $>98 \%$ and AF $>60 \%$ for species delineation. On this basis, some members of the R. erythropolis genome cluster groups, including strains currently named as $R$. enclensis, $R$. baikonurensis, R. opacus and R. rhodochrous, would be reclassified either as R. erythropolis or R. qingshengii.
\end{abstract}

Keywords: Actinobacteria; Rhodococcus erythropolis; Rhodococcus qingshengii; Williamsia; DNA extraction; next-generation sequencing; mycolic acids; ANI; psychrotrophic

\section{Introduction}

Contemporary genome sequencing technologies, described as third- and next-generation sequencing (such as single molecule real-time (SMRT) sequencing) facilitate the assembly of complex genomes by generating read lengths of $>10 \mathrm{~kb}$ [1]. Increasingly, these technologies require high-molecular weight genomic DNA (gDNA) templates. High-quality and high-molecular weight DNA is also recommended for short reading length using nextgeneration sequencing technologies [2,3]. However, some Gram-positive bacterial cells are very difficult to disrupt, particularly species of Actinobacteria in the order Corynebacteriales, which includes the genera Mycobacterium, Corynebacterium, Rhodococcus, Williamsia, Nocardia and Gordonia. Species within these genera are of biotechnological interest due to their broad catalytic activity in degrading toxic and persistent pollutants [4-6], synthesis of storage compounds with potential as biofuels (including triacylglycerols) or specialty chemicals [7-9] and synthesis of bioactive compounds and enzymes of pharmacological interest or with industrial applications $[10,11]$. The Corynebacteriales are highly or partially resistant to lysozyme due to their complex, lipid-rich cell envelopes which include mycolic acids covalently bound to arabinogalactan thence peptidoglycan [12]. gDNA extraction often requires prolonged enzymatic digestion, use of several enzymes and sometimes other 
chemical or mechanical interventions [13], which may result in fragmented DNA. Different commercial kits are available to extract high-quality gDNA with specific instructions for 'hard-to-lyse' bacteria, replacing conventional phenol chloroform extraction methods developed in the 1960s [14] and modified subsequently for different organisms [15]. However, variations in DNA yield and quality can occur [16], often necessitating optimizing conditions for lysis and DNA extraction for different species [17,18].

After failing to extract gDNA suitable for shotgun genome sequencing from six lysozyme-resistant sub-Antarctic Corynebacteriales strains, including testing various enzymatic and chemical treatments in combination with kit-based methods and alternative purification protocols, we investigated whether prior culture in glycine-supplemented broth would improve cell lysis. Growth in glycine-supplemented media is known to reduce peptidoglycan cross-linking so the structure is more amenable to lysozyme digestion [19] and has been employed previously to improve spheroplast formation in Mycobacterium spp. [20] and as a pre-treatment for improving DNA uptake by electroporation in Corynebacterium glutamicum [21].

We report the impact of prior growth conditions on the quality of gDNA extracted from the six environmental isolates of Corynebacteriales, as evaluated from fragment size and size distribution, using a modified, optimized classical extraction method [14] which was later compared with three commercial gDNA extraction kits. The gDNA prepared using the classical method met the quality criteria for using genome data for taxonomic purposes in prokaryotes [22] and genome sequencing confirmed the preliminary taxonomic delineation obtained by $16 \mathrm{~S}$ rRNA gene sequencing. While two Williamsia and two Rhodococcus strains were deemed novel species, based on ANI and phylogenomic analyses, two sub-Antarctic strains were classified as R. qingshengii (1139) and R. erythropolis (1159). There is increasing evidence that several validly published species of Rhodococcus in the 'erythropolis' mRNA sequence cluster [23] are later heterotypic synonyms, including species designated as R. degradans, R. enclensis and R. jialingiae [24-26]. Consequently, the biochemical and physiological properties of strains 1139 and 1159 were determined to document the properties of these psychrotrophic strains, including modelling the lowest temperature of growth. Species delineation points based on ANI and AF analyses for Rhodococcus in the 'erythropolis' genome clusters are discussed.

\section{Materials and Methods}

\subsection{Bacterial Strains and Culture Conditions}

The six strains from the University of Tasmania (Australia) sub-Antarctic culture collection (four identified as Rhodococcus spp., 1139, 1159, 1163 and 1168, and two as Williamsia spp., 1135 and 1138) [27-29] were cultured in a minimal salts media (MSM) consisting of a basal salts solution (BSS) including $7 \mathrm{~g} / \mathrm{L} \mathrm{K}_{2} \mathrm{HPO}_{4}, 2 \mathrm{~g} / \mathrm{L} \mathrm{KH}_{2} \mathrm{PO}_{4}, 0.25 \mathrm{~g} / \mathrm{L}$ sea salt (Instant Ocean, Blacksburg, VA, USA), $2 \mathrm{~g} / \mathrm{L}$ nitrogen source, $10 \mathrm{~g} / \mathrm{L}$ carbon source, $0.01 \mathrm{~g} / \mathrm{L} \mathrm{FeSO}_{4}$ and $10 \mathrm{mg} / \mathrm{L}$ thiamine hydrochloride (Sigma-Aldrich, Castle Hill, NSW, Australia). For routine culture of bacterial strains and the control strain $R$. corynebacteriodes, the nitrogen source used was $\mathrm{NH}_{4} \mathrm{H}_{2} \mathrm{PO}_{4}$ while the carbon source was $D$-fructose (MSM-F). The sub-Antarctic strains are available in the Belgium BCCM/LMG collection: 1139 = LMG 32064; 1159 = LMG 32063.

To determine the impact of glycine on bacterial growth, $300 \mu \mathrm{L}$ MSM-F (final volume) supplemented with up to $6 \%(w / v)$ glycine (MSM-G) was inoculated with mid-exponential phase cells to an initial optical density at $600 \mathrm{~nm}\left(\mathrm{OD}_{600}\right)$ of 0.1 in a 100 -well Bioscreen plate. $\mathrm{OD}_{600}$ was recorded every $2 \mathrm{~h}$ for up to 18 days at $25^{\circ} \mathrm{C}$ using Bioscreen-C instrumentation (Oy Growth Curves Ab Ltd., Helsinki, Finland) for triplicate cultures. Maximum specific growth rates $\left(\mu_{\max }\right)$ were calculated using Monod equations [30] and standard deviations calculated.

To extract gDNA for sequencing, strains were initially cultured in $30 \mathrm{~mL}$ MSM-F at $25^{\circ} \mathrm{C}$ at $200 \mathrm{rpm}$ then mid-exponential phase cells collected by centrifugation at 10,000 rcf for $5 \mathrm{~min}$. Cells were resuspended in $50 \mathrm{~mL}$ MSM-G with varying concentrations of MSM-G 
(4.5\% for Williamsia sp. 1138 and the four Rhodococcus spp.; 4.0\% for Williamsia sp. 1135) with incubation continued until the initial $\mathrm{OD}_{600}$ doubled. Escherichia coli strain M13 was used as a positive control for gDNA extraction using the kits and was cultured in Nutrient Broth (Oxoid, Thermo Fisher Scientific Australia Pty Ltd., Scoresby, VIC, Australia).

\subsection{Benchmarking Extraction and Purification of $g D N A$}

Due to its demonstrated recalcitrance to lysis, Williamsia sp. strain 1138 was chosen to determine the effects on the quality of extracted DNA following prior culture in glycinesupplemented media (0, 2.0 and 4.5\% MSM-G). Three commercial kits were used in this study (Method 1: ISOLATE II Genomic DNA Kit (Bioline, Alexandria, NSW, Australia); Method 2: Ultraclean Microbial DNA Isolation Kit (MO BIO Laboratories, Inc., Carlsbad, CA, USA); and Method 3: QIAamp ${ }^{\circledR}$ DNA Mini Kit (QIAGEN GmbH, Hilden, Germany)) and a classical method (Method 4).

Williamsia sp. 1138 and E. coli cells were collected from $50 \mathrm{~mL}$ of culture by centrifugation (10,000 rcf for $5 \mathrm{~min}$ ) and cell pellets resuspended in $0.01 \mathrm{M}$ Tris buffer ( $\mathrm{pH} 8$ ) to concentrate to an $\mathrm{OD}_{600}$ of 4.5. Triplicate aliquots of $1 \mathrm{~mL}$ were transferred into $1.5 \mathrm{~mL}$ microcentrifuge tubes for each treatment and growth condition, then cells were collected by centrifugation as described above and resuspended in buffers as specified in each protocol. DNA was extracted according to instruction manuals for hard-to-lyse bacteria except for elution steps, when DNA was eluted in smaller volumes of elution buffer to increase final DNA concentrations. Genomic DNA was extracted from E. coli according to the instruction manuals for bacteria.

For the classical extraction method (Method 4), based on approaches originally described by Marmur [14], cells were resuspended in $180 \mu \mathrm{L} 0.05 \mathrm{M}$ Tris/EDTA buffer, $\mathrm{pH}$ 8, supplemented with 20\% sucrose. Lysozyme $(200 \mu \mathrm{g} / \mathrm{mL})$ (Sigma-Aldrich, Castle Hill, NSW, Australia) was added followed by incubation at $37^{\circ} \mathrm{C}$ for $2 \mathrm{~h}$ (with $4-5$ inversions during incubation). Lysozyme-treated cells were collected by centrifugation at 15,000 rcf for $5 \mathrm{~min}$ and resuspended into $600 \mu \mathrm{L}$ Tris/EDTA buffer containing $60 \mu \mathrm{g} / \mathrm{mL}$ proteinase K, $100 \mu \mathrm{g} / \mathrm{mL}$ DNase-free RNase and 1\% SDS (all reagents from Sigma-Aldrich, Castle Hill, NSW, Australia), then incubated at $55{ }^{\circ} \mathrm{C}$ for $1 \mathrm{~h}$. Subsequently, $600 \mu \mathrm{L}$ of chloroform/iso-amyl alcohol $(24 / 1, v / v)$ was mixed with the viscous solution, then the emulsion separated by centrifugation at 15,000 rcf for $30 \mathrm{~min}$. The top layer was carefully collected into a new tube by pipetting and the extraction repeated twice. After the final collection of the aqueous phase, two volumes of ice-cold ethanol and ammonium acetate $(0.3 \mathrm{M}$ final concentration from a $3 \mathrm{M}$ solution) were added to precipitate DNA. After $5 \mathrm{~min}$ on ice, the precipitate was collected $\left(12,000 \mathrm{rcf}, 4^{\circ} \mathrm{C}, 10 \mathrm{~min}\right)$ then the supernatant carefully discarded without disturbing the DNA pellet. The DNA pellet was washed twice with $500 \mu \mathrm{L}$ of $70 \%$ $(v / v)$ ice-cold ethanol to remove the salts, centrifuged for $1 \mathrm{~min}$ at 12,000 $\mathrm{rcf}$, then the pellet was air dried for 10 min prior to resuspending into $50 \mu \mathrm{L}$ of $0.01 \mathrm{M}$ Tris buffer ( $\mathrm{pH} 8$ ).

\subsection{Quantity, Fragment Size and Purity of Extracted DNA}

Preliminarily, DNA concentration was estimated from absorbance at $260 \mathrm{~nm}$ with protein contamination being determined from the $\mathrm{A}_{260} / \mathrm{A}_{280}$ and other organic contamination determined by $\mathrm{A}_{260} / \mathrm{A}_{230}$ ratio (NanoDrop 8000 Spectrophotometer, Thermo Fisher Scientific Australia Pty Ltd., Scoresby, VIC, Australia).

Quantity and fragment size of extracted DNA was assessed using a DNA Fragment Analyser (Advanced Analytical Technologies, Inc, Orangeburg, NY, USA) and the PROSize ${ }^{\circledR}$ 2.0 software was used to analyse data, including imaging each electrophoretogram. A DNF-487-33-SS Genomic DNA kit (Advanced Analytical Technologies, Inc., Orangeburg, NY, USA) was used as internal standard to ascertain size and quantity of DNA. The lower marker (LM) was set to 1 base pair (bp) and 10,000 bp was set as the threshold for DNA quality number (GQN). The PROSize ${ }^{\circledR} 2.0$ software scores the GQN value $0-10$ based on the percentage of DNA above the set threshold. 


\section{4. gDNA Sequencing and Quality Assessment}

gDNA was prepared for all the strains from $50 \mathrm{~mL}$ cultures, grown in 4 or $4.5 \%$ MSM$\mathrm{G}$, as described in Section 2.2, Method 4, with slight variation. After lysozyme treatment, cells collected from strains Williamsia sp. 1135, Williamsia sp. 1138, Rhodococcus sp. 1139 and Rhodococcus sp. 1159 were incubated with proteinase $\mathrm{K}$ for $1 \mathrm{~h}$ to achieve complete lysis (visual clearing of turbidity), and for 3-4 h for strains Rhodococcus sp. 1163 and Rhodococcus sp. 1168. Extracted gDNA samples were sent to Macrogen Inc (Seoul, Republic of South Korea) for MiSeq Illumina sequencing, which included quality assessment. A 670-bp sizebased TruSeq Nano DNA (550) Library was prepared and Illumina SBS technology used to generate $2 \times 300$-bp paired-end reads. MiSeq Control Software v2.2 (MCS) was used to generate raw data and Real Time Analysis software (v1.18) was used for base calling. To access the sequencing data quality, the base calling accuracy was measured by phred quality score (Q score).

\subsection{5 rRNA Gene Sequencing and Preliminary Phylogenetic Analysis}

The ISOLATE II Genomic DNA Kit (Bioline, Alexandria, NSW, Australia) was used to extract DNA from mid-exponential phase cultures (without glycine supplementation) according to the manufacturer's directions for hard-to-lyse bacteria. The universal primers 27F and 16S-1492R (Sigma-Aldrich, Castle Hill, NSW, Australia) were used to amplify a 1465-bp segment of the 16S rRNA gene. PCR products were sequenced by Macrogen Inc. Sequences were analysed using the nucleotide BLAST function of the National Centre for Biotechnology Information (NCBI) and the closest match was determined to assign probable identities. Multiple sequence alignment option CLUSTALW (https: / / www.ebi.ac.uk/Tools/msa/clustalo/) was used to align the 16S rRNA sequences and a neighbour-joining phylogenetic tree was performed using DNADIST v3.5c program of BioEdit software (v7.2.5) [31] to determine their position within the genus.

\subsection{Genome Sequence Analyses to Identify Rhodococcus Species}

The sequenced genomes of all six sub-Antarctic strains were examined using tools available in the Integrated Microbial Genomics and Microbiomes (IMG/M) database (https:/ /img.jgi.doe.gov/cgi-bin/mer/main.cgi, accessed most recently in May 2021) [32] for pairwise ANI and genome-clustering analyses plus phylogenetic tree construction using hierarchical clustering based on pfam and COG functions. IMG/M genome identification numbers are in order of our strain numbers 1135-1168: 2724679737, 2775507282, 2724679739, 2816332322, 2724679741 and 2724679742. Pairwise ANI comparisons were made using the NCBI reference genome for $R$. erythropolis (CCM 2595), a recently sequenced genome of $R$. qingshengii TUHH-12 [33], and type strains of both species, R. erythropolis NBRC 15567 (= JCM $3201=$ ATCC 4277) and R. qingshengii (JCM 15477 and Djl-6-2) (from the List of Prokaryotic names with Standing in Nomenclature, https://lpsn.dsmz.de/, accessed January 2021) [34]. Genomes of other strains which were detected as similar to the query isolates by $16 \mathrm{~S}$ rRNA gene sequencing were selected for comparison from the Rhodococcus species listed on IMG/M. As the whole genomes of some species that were most closely related to strains Rhodococcus sp. 1163 and 1168 (based on 16S rRNA gene sequences) were not available when this research was undertaken, a neighbour-joining phylogenetic tree based on the alkB gene was prepared using MEGA7 software [35]. Multiple sequence alignment option MUSCLE in the MEGA7 software was used to align the alkB gene sequences. AlkB is a key protein in the alkane-degrading pathway and the gene is used as a phylogenetic marker to differentiate closely related Rhodococcus species [36].

\subsection{Biochemical Characterization of Strains 1139 and 1159 \\ 2.7.1. Enzymatic Tests to Characterize Bacterial Strains}

To detect the enzymatic activities of bacterial strains, the semi-quantitative micromethod API ZYM (bioMérieux, North Ryde, NSW, Australia) was used, where each strip contained 20 cupules (19 enzymatic substrates and 1 control). Bacterial cells grown in MSM- 
F were collected by centrifugation at 10,000 rcf for $5 \mathrm{~min}$, washed with sterile phosphatebuffered saline (PBS) and resuspended in PBS with $\mathrm{OD}_{600}$ adjusted to 0.5. Optical density was measured using an Ultraspec spectrophotometer (BMG Labtech Pty. Ltd., Mornington, Australia). Aliquots of $65 \mu \mathrm{L}$ of this suspension were transferred aseptically into each cupule of the supplied API strip, incubated overnight at $25^{\circ} \mathrm{C}$ and reagents were added according to manufacturer's directions. Results were recorded in values ranging from 0 to 5 according to the degree of color development, where 0 corresponds to a negative reaction and 5 corresponds to maximum intensity.

\subsubsection{Growth on Different Carbon and Nitrogen Sources and Impact of Phosphate Concentration on Growth}

To compare growth rates on different carbon sources, the Rhodococcus strains 1139 and 1159 were grown initially in $30 \mathrm{~mL}$ of MSM-F at $25^{\circ} \mathrm{C}, 200 \mathrm{rpm}$, to mid-log phase. The $\mathrm{OD}_{600}$ was measured, then cells collected by centrifugation at 10,000 rcf for $5 \mathrm{~min}$. After decanting the supernatant, cells were washed twice with BSS and incubated for $24 \mathrm{~h}$ in the same solution at $25^{\circ} \mathrm{C}$ and $200 \mathrm{rpm}$ agitation. The cell suspensions were centrifuged again, and pellets were resuspended in a volume of BSS to concentrate cells to an $\mathrm{OD}_{600}$ of approximately 10 . This suspension was then used to inoculate $297 \mu \mathrm{L}$ MSM containing $1 \%(w / v)$ of different carbon sources to adjust the final volume to $300 \mu \mathrm{L}$ with an initial $\mathrm{OD}_{600}$ of 0.1 in a 100 well Bioscreen plate with three replicates for each test. The Bioscreen $\mathrm{C}$ instrument was set at $25^{\circ} \mathrm{C}$ with continuous medium amplitude shaking. A grey filter with $600 \mathrm{~nm}$ wavelength was selected to record the OD at 2-h intervals for up to 12 days. The maximum readable $\mathrm{OD}_{600}$ with this system was 3.5 .

To compare bacterial growth on different nitrogen sources, MSM-F was prepared with $0.2 \%(w / v)$ of different organic and inorganic nitrogen sources, plus combinations of these. Double-strength BSS was sterilized by autoclaving and filter-sterilized carbon and nitrogen sources were added from $20(w / v)$ and $2 \%(w / v)$ stock solutions, respectively, with the final volume adjusted with sterile distilled water to produce single-strength MSM. Bacterial strains were inoculated, and growth was observed using the automated Bioscreen system as described above. When the nitrogen source in MSM-F broth, $\mathrm{NH}_{4} \mathrm{H}_{2} \mathrm{PO}_{4}$, was replaced by alternative nitrogen sources, the concentration of phosphate ion $(6.8 \mathrm{~g} / \mathrm{L})$ was concurrently reduced by $25 \%$ (to $5.2 \mathrm{~g} / \mathrm{L}$ ). To evaluate the impact of phosphate concentration on growth, a second series of MSM-F media with the different nitrogen sources was prepared by adjusting the composition of BSS to contain $9.41 \mathrm{~g} / \mathrm{L} \mathrm{K} \mathrm{HPO}_{4}$ and $2.52 \mathrm{~g} / \mathrm{L} \mathrm{KH}_{2} \mathrm{PO}_{4}$ (6.8 $\mathrm{g} / \mathrm{L}$ phosphate ion), including when $\mathrm{NH}_{4} \mathrm{H}_{2} \mathrm{PO}_{4}$ was used as nitrogen source (total phosphate ion $8.5 \mathrm{~g} / \mathrm{L}$, or a $25 \%$ increase above MSM-F). This second set of media is described as 'phosphate-adjusted'.

\subsubsection{Salt Tolerance Testing}

To evaluate salt tolerance, double-strength BSS- $\mathrm{NH}_{4} \mathrm{H}_{2} \mathrm{PO}_{4}$ was supplemented with 0 to $15 \% \mathrm{NaCl}$ from a $25 \%(w / v)$ filter sterilized $\mathrm{NaCl}$ stock solution. $D$-fructose, thiamine hydrochloride and $\mathrm{FeSO}_{4}$ were supplemented as for regular MSM, and then the volume adjusted to single-strength MSM with sterile distilled water. The strains were inoculated and cultured using the Bioscreen system as described above.

\subsubsection{Determining Optimum Temperature for Growth in MSM-F Broth}

Growth rates for temperatures in the range between 0 and $45^{\circ} \mathrm{C}$ were determined in shake-flask cultures. To prepare starter cultures, a single colony was picked from an NA streak-plate and inoculated into $30 \mathrm{~mL}$ MSM-F broth in $100 \mathrm{~mL}$ conical flasks and cultured at $25^{\circ} \mathrm{C}, 200 \mathrm{rpm}$. At mid-log phase, the starter was sub-cultured into $100 \mathrm{~mL}$ MSM-F broth to give an initial $\mathrm{OD}_{600}$ of 0.06 . Optical density was recorded periodically during incubation against the medium blank for up to 4 months depending on temperature. Cultures were diluted 10- or 100-fold in the same medium when the $\mathrm{OD}_{600}$ reached above 0.9 (within the linear range of turbidity for the spectrophotometer). All tests were performed in triplicate. 


\subsubsection{Modelling Minimum and Maximum Growth Temperatures}

Growth rate $\left(\mu_{\max }\right)$ was calculated from the natural logarithm of $\mathrm{OD}_{600}$ for MSM-Fgrown cells: $\mu_{\max }=(\mathrm{Ln} N 2-\mathrm{Ln} \mathrm{N} 1) /(\mathrm{t} 2-\mathrm{t} 1)$, where $\mathrm{N}=$ cell concentration and $\mathrm{t}=$ time (30). Generation time (GT) (h) was calculated by dividing the natural logarithm of 2 by $\mu_{\max }\left(\mathrm{h}^{-1}\right)$ : GT $=\mathrm{Ln} 2 / \mu_{\max }$. Generation times at different temperature were used to fit the nonlinear model [37] below using the function nlsLM in the library minpack.lm using the software program $\mathrm{R}$ version 3.3 [38]. The experimentally determined and model-predicted values were plotted against temperature. The fitted function was:

$$
\sqrt{\mathrm{r}}=\mathrm{b} \times\left(\mathrm{T}-\mathrm{T}_{\min }\right) \times\left(1-\exp \left(\mathrm{c} \times\left(\mathrm{T}-\mathrm{T}_{\max }\right)\right)\right.
$$

where $\mathrm{r}=$ observed growth rate, $\mathrm{T}=$ temperature $\left({ }^{\circ} \mathrm{C}\right)$ and $\mathrm{b}, \mathrm{c}, \mathrm{T}_{\min }$ and $\mathrm{T}_{\max }$ are regression coefficients. The $\mathrm{T}_{\min }$ and $\mathrm{T}_{\max }$ represent the temperatures at which growth is zero. The model was fitted to the square root of the growth rate to homogenize variance.

\subsubsection{Triacylglycerol (TAG) Analysis}

Positive ESI technique was used to identify TAG with UPLC-MS/MS. A Waters Acquity UPLC BEH C18 column $(2.1 \mathrm{~mm} \times 100 \mathrm{~mm} \times 1.7 \mu \mathrm{m})$ was used. The UPLC solvent program consisted of solvent A $100 \mathrm{mM}$ ammonium acetate ( $\mathrm{pH}$ 5), solvent B acetonitrile and solvent $C$ methanol:hexane $(8: 2, v / v)$. The solvent gradient was: $100 \%$ $\mathrm{A} / \mathrm{B}(2: 8, v / v)$ from $0 \mathrm{~min}$ to $100 \% \mathrm{~B}$ at $2 \mathrm{~min}$; followed by a linear gradient to $100 \% \mathrm{C}$ at $8 \mathrm{~min}$, which was held for $14 \mathrm{~min}$ before returning to initial conditions. The total flow was $0.5 \mathrm{~mL} / \mathrm{min}$ for $2 \mathrm{~min}$ followed by an immediate ramp to $0.6 \mathrm{~mL} / \mathrm{min}$. A post-column infusion of $5 \%(v / v)$ ammonium hydroxide solution was employed at a rate of $3 \mu \mathrm{L} / \mathrm{min}$ to induce the formation of $\left[\mathrm{M}+\mathrm{NH}_{4}\right]^{+}$molecular species. TAG molecular species were detected in full scan mode over the mass range $(\mathrm{m} / \mathrm{z}) 100$ to 1050 at three simultaneous cone voltages $(20,45$ and $70 \mathrm{~V})$. The higher cone voltages were used to induce in-source fragmentation for partial identification of TAG acyl residues [39].

\subsubsection{Fatty Acid Methyl Ester (FAME) Analysis by GC-MS}

FAMEs were analysed by gas chromatography-mass spectrometry (GC-MS) consisting of a Varian 3800 GC and a Bruker 300 triple quadrupole MS fitted with a $30 \mathrm{~m}$ $\times 0.25 \mathrm{~mm}$ Agilent VF-5MS column $(0.25 \mu \mathrm{m}$ film thickness, bound fused silica, Agilent Technologies, Santa Clara, CA, USA) and using helium $(1.3 \mathrm{~mL} / \mathrm{min})$ as the carrier gas. A $1 \mu \mathrm{L}$ portion of sample was injected with a 30:1 split ratio. The injection port was kept at $290{ }^{\circ} \mathrm{C}$. The oven temperature was initially $50^{\circ} \mathrm{C}$ for $1 \mathrm{~min}$ and then programmed to heat at a rate of $30{ }^{\circ} \mathrm{C} / \mathrm{min}$ to reach $150{ }^{\circ} \mathrm{C}$, then $2{ }^{\circ} \mathrm{C} / \mathrm{min}$ to reach $250{ }^{\circ} \mathrm{C}$ and after that, $5{ }^{\circ} \mathrm{C} / \mathrm{min}$ to reach the final temperature $320{ }^{\circ} \mathrm{C}$ for $5 \mathrm{~min}$. Star software was used to control the operation of the GC-MS. Full-scan MS spectra in the range of $(\mathrm{m} / z) 35$ to 450 was obtained. Individual FAMEs were identified by comparison of retention times and mass spectra with those of standard FAME (NIST/EPA/NIH Mass Spectral Library 2017). Relative amounts of each FAME were calculated as a percentage of the total amount (peak area) detected.

\subsection{Analysis of Mycolic Acids (MA)}

Bound and unbound MA were identified by UPLC-triple quadruple mass spectrometry (UPLC-MS/MS) in negative electrospray ionization (ESI) mode using a Waters Acquity H-Class UPLC instrument coupled to a Waters Xevo TQ MS/MS (Waters Corporation, Milford, MA, USA). A Waters Acquity UPLC BEH C18 column $(2.1 \mathrm{~mm} \times 100 \mathrm{~mm} \times 1.7 \mu \mathrm{m})$ was used (Waters Corporation). The solvents for UPLC consisted of solvent A, acetonitrile containing $1 \mathrm{mM}$ acetic acid, and solvent $\mathrm{B}$, isopropanol:hexane $(8: 2, v / v)$. Initial conditions were $100 \%$ solvent A for $1 \mathrm{~min}$, before a gradient elution to $100 \%$ solvent B over $14 \mathrm{~min}$, which was held for $5 \mathrm{~min}$ before returning to initial conditions and equilibrating for $3 \mathrm{~min}$. Total flow was $0.3 \mathrm{~mL} / \mathrm{min}$. For MA analysis the electrospray needle was set at $2.8 \mathrm{kV}$. The ion source temperature was $130{ }^{\circ} \mathrm{C}$, the desolvation gas was $\mathrm{N}_{2}$ at $950 \mathrm{~L} / \mathrm{h}$, the cone gas 
flow was $100 \mathrm{~L} / \mathrm{h}$ and the desolvation temperature was $450{ }^{\circ} \mathrm{C}$. MA molecular species were detected in full-scan mode experiments over the mass range $(\mathrm{m} / \mathrm{z}) 400$ to 1000 with a cone voltage of $60 \mathrm{~V}$. MS/MS product scan experiments were conducted from specific $[\mathrm{M}-\mathrm{H}]^{-}$ precursor molecules over an appropriate product ion range using a cone voltage of $60 \mathrm{~V}$ and collision energy of $45 \mathrm{~V}$. Data were processed using MassLynx software (version 4.1) (Waters Corporation).

\section{Results}

\subsection{Impacts of Glycine on Bacterial Growth}

The six sub-Antarctic strains demonstrated different sensitivity to growth inhibition by glycine when cultured in MSM-F broth (Figure 1). The majority were not impacted greatly by $1 \%$ glycine, with $\mu_{\max }$ values at $75-115 \%$ of the control. Although four of the strains demonstrated approximately 50\% inhibition at $2 \%$ glycine, Williamsia sp. 1138 and Rhodococcus sp. 1168 only showed similar inhibition when MSM-F broth was supplemented with $4 \%$ glycine. Williamsia sp. 1135 was more sensitive to growth inhibition by glycine, showing strong inhibition at $4 \%$ and failure to grow at $5-6 \%$ glycine. All the other strains grew in glycine concentrations up to $6 \%$, albeit at highly reduced $\mu_{\text {max }}$ values.

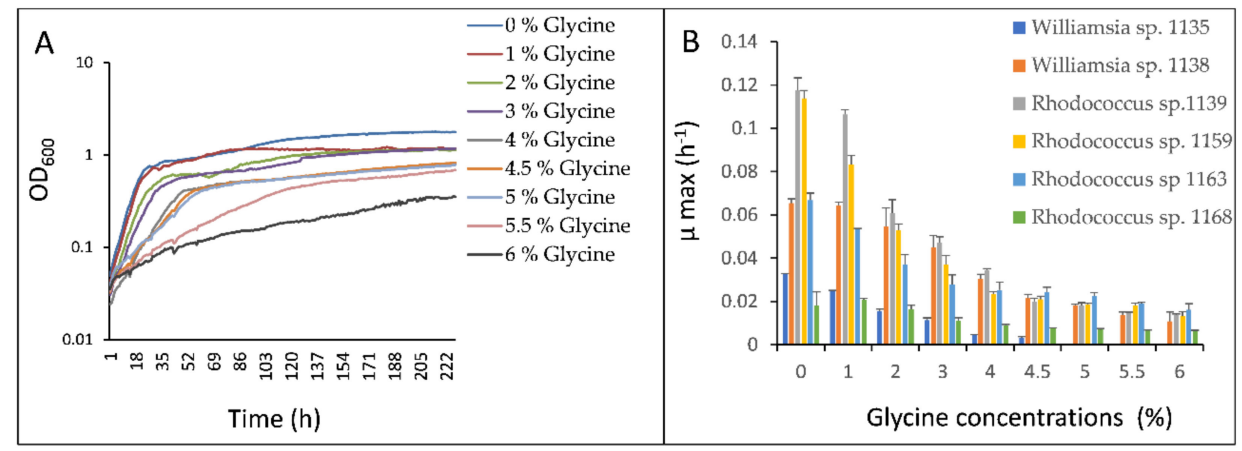

Figure 1. Impact of glycine on growth of six sub-Antarctic strains. (A) An example of growth kinetics of strain Williamsia sp. 1138 in MSM-F broth supplemented with different concentrations of glycine; (B) means and standard deviations of maximum specific growth rates $\left(\mu_{\max }\right)$ for six strains cultured in MSM-glycine broths.

\subsection{Quantity and Purity of Extracted DNA}

Fragment Analyser data indicated that all the column-based kits extracted highmolecular weight gDNA from E. coli, with an upper fragment size of 39 to $52 \mathrm{Kbp}$ for the different kits (Table 1). However, the smallest fragment sizes (1-7 Kbp) varied with the kits: a GQN number of 6.5, corresponding to the broadest fragment size range and lowest average fragment size, was obtained using the Isolate II Genomic DNA kit (Method 1), while the highest GQN number of 9.2 was found from the QIAAMP Mini kit (Method 3) (Table 1). E. coli gDNA yields were higher than seen for the Gram-positive Williamsia sp. 1138 (Table 1). These data validate the efficacy of all the kits with the E. coli control.

Prior culture of Williamsia sp. 1138 in glycine-supplemented broth improved both the yield (DNA concentration from the same starting biomass in each test) and GQN for all four methods. Excepting Method 3, prior culture in 4.5\% MSM-G improved both gDNA yield and GQN relative to culture in 0 and $\%$ MSM-G. However, Method 1 produced fragmented DNA from cells cultured in 0, 2 and 4.5\% MSM-G under the experimental conditions used (Table 1, Figure 2). The highest concentration of gDNA was isolated using Method 3, although the maximum DNA integrity (assessed in terms of average fragment size and tightest fragment size range, and a GQN of 9) was obtained by Method 4 for cells cultured in $4.5 \%$ MSM-G, as demonstrated by tight banding seen on gel images (Figure 2). Acceptable $\mathrm{A}_{260} / \mathrm{A}_{280}$ and $\mathrm{A}_{260} / \mathrm{A}_{230}$ ratios were obtained for most of the kit extracts and for gDNA obtained by Method 4 for $4.5 \%$ glycine-grown cells (Table 1 ). 
Table 1. Average scores for DNA quality and quantity following extraction from Williamsia sp. 1138 cells cultured in MSM supplemented with 0,2 and $4.5 \%$ glycine.

\begin{tabular}{|c|c|c|c|c|c|c|c|c|c|c|c|c|c|c|c|}
\hline \multirow[t]{2}{*}{ Parameters } & \multicolumn{4}{|c|}{$\begin{array}{c}\text { Method 1 } \\
\text { Isolate II Genomic DNA Kit (Bioline) }\end{array}$} & \multicolumn{4}{|c|}{$\begin{array}{c}\text { Method 2 } \\
\text { Ultraclean Microbial DNA Isolation Kit (MO } \\
\text { BIO) }\end{array}$} & \multicolumn{4}{|c|}{$\begin{array}{c}\text { Method 3 } \\
\text { QIAAMP Mini Kit (Qiagen) }\end{array}$} & \multicolumn{3}{|c|}{$\begin{array}{c}\text { Method } 4 \\
\text { Classical Extraction }\end{array}$} \\
\hline & $0 \%^{a}$ & $2 \%^{a}$ & $4.5 \%^{a}$ & E. coli & $0 \%^{a}$ & $2 \%^{a}$ & $4.5 \%^{a}$ & E. coli & $0 \%^{a}$ & $2 \%^{a}$ & $4.5 \%^{a}$ & E. coli & $0 \%^{a}$ & $2 \%^{a}$ & $4.5 \%^{a}$ \\
\hline $\begin{array}{c}\text { Mean } \\
\text { concentration } \\
\text { of DNA }(n g / \mu L) \\
\pm \text { s.d. } b\end{array}$ & $10 \pm 1$ & $39 \pm 3.2$ & $69 \pm 2$ & $295 \pm 2$ & $25.7 \pm 1.1$ & $45.7 \pm 4.9$ & $60.2 \pm 6.7$ & $74 \pm 3.5$ & $17 \pm 2.6$ & $42.2 \pm 3.2$ & $71.7 \pm 3.5$ & $79.4 \pm 2.5$ & $\begin{array}{c}1.5 \pm \\
0.35\end{array}$ & $6 \pm 1.64$ & $30.4 \pm 4.1$ \\
\hline $\begin{array}{c}\text { Mean GQN } \pm \\
\text { s.d. b }\end{array}$ & $\begin{array}{c}0.9 \pm \\
0.07\end{array}$ & $\begin{array}{c}1.0 \pm \\
0.3\end{array}$ & $0.2 \pm 0.4$ & $6.5 \pm 0.3$ & $5.9 \pm 0.06$ & $8.1 \pm 0.04$ & $8.4 \pm 0.12$ & $9.2 \pm 0.03$ & $6.5 \pm 0.56$ & $7.8 \pm 0.35$ & $7.6 \pm 0.35$ & $8.6 \pm 0.1$ & $\begin{array}{c}1.8 \pm \\
0.04\end{array}$ & $6.5 \pm 0.28$ & $9.0 \pm 0.07$ \\
\hline $\begin{array}{l}\text { Fragment size } \\
\text { range }(b p)^{b}\end{array}$ & $\begin{array}{l}823- \\
9763\end{array}$ & $\begin{array}{l}557- \\
1321\end{array}$ & $27-388$ & $\begin{array}{c}991- \\
39,079\end{array}$ & $\begin{array}{c}2019- \\
40,109\end{array}$ & $\begin{array}{l}2849- \\
54,726\end{array}$ & $\begin{array}{l}2755- \\
54,903\end{array}$ & $\begin{array}{l}1913- \\
48,525\end{array}$ & $\begin{array}{l}8549- \\
49,782\end{array}$ & $\begin{array}{r}7605- \\
55,301\end{array}$ & $\begin{array}{l}2891- \\
50,707\end{array}$ & $\begin{array}{l}6787- \\
52,428\end{array}$ & $0-14$ & $\begin{array}{c}22,636- \\
44,933\end{array}$ & $\begin{array}{l}16,591- \\
42,748\end{array}$ \\
\hline $\begin{array}{c}\text { Average } \\
\text { fragment size } \\
(\mathrm{bp})^{\mathrm{b}}\end{array}$ & 9554 & 490 & 128 & 13,975 & 21,246 & 18,923 & 17,284 & 26,027 & 24,249 & 26,555 & 23,410 & 32,406 & 2.0 & 33,581 & 28,430 \\
\hline $\begin{array}{c}\text { Mean } \mathbf{A}_{260} / \mathbf{A}_{280} \\
\pm \text { s.d. } \\
\end{array}$ & $\begin{array}{c}2.0 \pm \\
0.09\end{array}$ & $\begin{array}{c}2.0 \pm \\
0.04\end{array}$ & $2.0 \pm 0.06$ & $2.1 \pm 0.03$ & $2.0 \pm 0.02$ & $\begin{array}{c}1.99 \pm \\
0.04\end{array}$ & $1.88 \pm 0$ & $\begin{array}{c}1.98 \pm \\
0.03\end{array}$ & $\begin{array}{l}2.1 \pm \\
10.04\end{array}$ & $2.1 \pm 0.01$ & $2.1 \pm 0.01$ & $2.1 \pm 0.09$ & $\begin{array}{c}1.96 \pm \\
0.09\end{array}$ & $\begin{array}{c}1.69 \pm \\
0.04\end{array}$ & $\begin{array}{c}1.70 \pm \\
0.06\end{array}$ \\
\hline $\begin{array}{c}\text { Mean } A_{260} / A_{230} \\
\pm \text { s.d. }^{c}\end{array}$ & $\begin{array}{c}2.1 \pm \\
0.03\end{array}$ & $\begin{array}{c}1.9 \pm \\
0.12\end{array}$ & $1.8 \pm 0.03$ & $1.9 \pm 0.06$ & $1.3 \pm 0.12$ & $1.4 \pm 0.16$ & $1.6 \pm 0.06$ & $1.6 \pm 0.09$ & $1.1 \pm 0.03$ & $2.1 \pm 0.03$ & $2.1 \pm 0.03$ & $2.1 \pm 0.06$ & $\begin{array}{c}0.91 \pm \\
0.3\end{array}$ & $\begin{array}{c}1.65 \pm \\
0.12\end{array}$ & $\begin{array}{c}1.71 \pm \\
0.03\end{array}$ \\
\hline
\end{tabular}

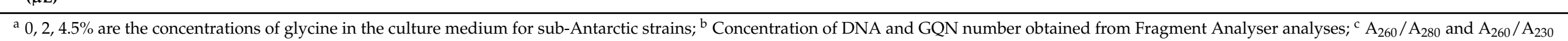
ratio were obtained from NanoDrop spectrophotometry; s.d. = standard deviation. 

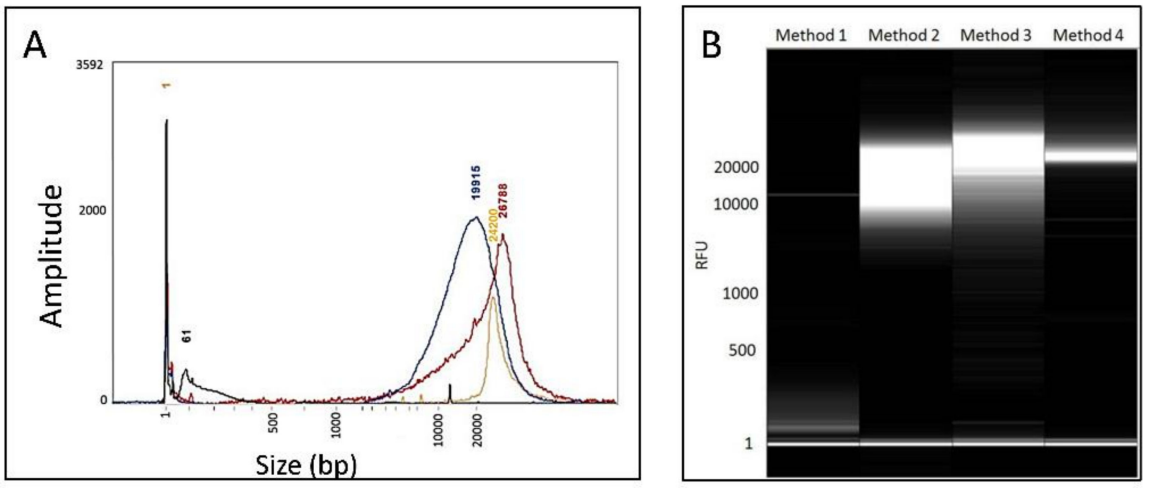

Figure 2. DNA fragment size analyses for four extraction methods of Williamsia sp. 1138 cells cultured in 4.5\% MSM-G. (A) Amplitude readout from the Fragment Analyser and (B) images generated from the automated capillary electrophoresis system of the Fragment Analyser with size standards (bp) marked. Method 1: Isolate II Genomic DNA kit (Bioline) (_ peaks at 61 and 12,000 bp; Method 2: Ultraclean Microbial DNA Isolation kit (MO BIO) (_ peak at 19,915 bp); Method 3: QIAAMP Mini kit (Qiagen) (_ peak at 26,788 bp); Method 4: Classical extraction method (_ peak at 24,200 bp).

\subsection{DNA Sequencing and Quality Score of Sequenced DNA}

The classical gDNA extraction method was subsequently applied to all six subAntarctic strains using $50 \mathrm{~mL}$ cultures of MSM-G with 4.0 or $4.5 \%$ glycine and DNA submitted for shotgun sequencing. The quality of the DNA was high (as assessed from high average DNA fragment size, GQN number and absorbance 260/280 and 260/230 ratios) (Table 2). A total of 1.9, 1.8, 1.7, 1.7, 1.8 and $1.9 \mathrm{~Gb}$ read bases with over $60 \%$ Q30 score were obtained for Williamsia spp. 1135 and 1138 and Rhodococcus spp. 1139, 1159, 1163 and 1168, respectively. Raw data from Macrogen Inc was assembled using ABySS software [27-29] and submitted to DDBJ/EMBL/GenBank under the accession numbers: MJEI00000000; MJEJ00000000; LWHK00000000; MJVD00000000; MKKX00000000; and MKKY00000000.

Table 2. Quality and quantity scores for gDNA obtained from large-scale (50 mL) cultures of six sub-Antarctic strains.

\begin{tabular}{|c|c|c|c|c|c|c|c|c|c|c|c|}
\hline Strain Name & $\mathrm{ng} / \mu \mathrm{L}^{\mathrm{a}}$ & $\mathrm{GQN}^{\mathrm{a}}$ & 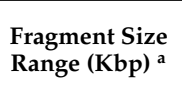 & $\begin{array}{c}\text { Average } \\
\text { Size } \\
(\mathrm{Kbp})^{a}\end{array}$ & $\underset{260 / 280^{b}}{A}$ & $\underset{260 / 230^{b}}{A}$ & $\begin{array}{l}\text { Q30 } \\
(\%)^{c}\end{array}$ & $\begin{array}{l}\text { N50d } \\
\text { (Kbp) }\end{array}$ & L50 ${ }^{d}$ & $\underset{d}{\text { Contigs }}$ & $\begin{array}{c}\text { GC } \\
\text { Content } \\
(\%)^{d}\end{array}$ \\
\hline Williamsia sp. 1135 & 66.1 & 8.1 & $13.28-44.50$ & 28.721 & 1.92 & 1.84 & 64.36 & 142.77 & 14 & 109 & 64.7 \\
\hline Williamsia sp. 1138 & 319 & 9.8 & $57.24-62.78$ & 59.424 & 1.93 & 1.93 & 63.92 & 191.09 & 12 & 54 & 64.8 \\
\hline R. qingshengii 1139 & 169.7 & 9.3 & $41.57-56.44$ & 48.133 & 1.94 & 1.75 & 62.70 & 94.97 & 24 & 192 & 62.3 \\
\hline R. erythropolis 1159 & 106.2 & 8.7 & $11.63-48.44$ & 27.142 & 1.78 & 1.78 & 65.11 & 196.55 & 13 & 114 & 62.3 \\
\hline Rhodococcus sp. 1163 & 40.5 & 8.7 & $15.73-47.69$ & 32.799 & 1.99 & 1.87 & 64.67 & 329.55 & 5 & 43 & 62.3 \\
\hline Rhodococcus sp. 1168 & 66.3 & 9.5 & $9.72-51.78$ & 27.334 & 2.01 & 1.88 & 66.25 & 154.59 & 10 & 97 & 62.1 \\
\hline
\end{tabular}

${ }^{a}$ DNA concentration and GQN obtained from Fragment Analyser data. ${ }^{\mathrm{b}} \mathrm{A}_{260} / \mathrm{A}_{280}$ and $\mathrm{A}_{260} / \mathrm{A}_{230}$ ratio were obtained by Nano Drop spectrophotometry. ${ }^{\mathrm{c}}$ Obtained from Macrogen: Q30 is the \% of reads that have a phred quality score of over $30 .{ }^{\mathrm{d}}$ Obtained after assembly using ABySS software; N50 is the length of the shortest contig that provides $50 \%$ of the genome when information in contigs above this size is summed [1]; DNA GC content of assembled sequences.

\subsection{Preliminary Strain Identification Based on Sequencing $16 S$ rRNA Gene PCR Amplicons}

The BLAST search results based on the $16 \mathrm{~S}$ rRNA gene sequences indicated that strains 1135 and 1138 belonged to the genus Williamsia, while the other strains belonged to the genus Rhodococcus (Figure 3A). Known species of Williamsia formed two distinct clades with strains 1135 and 1138 demonstrating $99 \%$ similarity with the clade containing species of $W$. muralis, W. faeni, W. marianensis and W. limnetica. While most closely related to W. limnetica, strains 1135 and 1138 were distinct from this species and from each other based on the 16S rRNA neighbour-joining tree (Figure 3A). The sequence of the $16 \mathrm{~S}$ rRNA PCR products from strains 1139 and 1159 showed 99 and 100\% similarity, respectively, with R. erythropolis R138 and clustered with a group of Rhodococcus species including R. erythropolis, R. qingshengii, $R$. baikonurensis and $R$. degradans. Strain 1163 had $99 \%$ similarity with $R$. fascians strain IHBB 
9283 and R. yunnanensis strain R-36475. Strain 1168 had 99\% similarity with $R$. fascians IHBB 9283, R. cercidiphylli EB37, R. cerastii BZ22 and R. yunnanensis IHBB 9867. Rhodococcus strains 1163 and 1168 each formed separate clades in 16S rRNA gene neighbour-joining trees. Assigning strain identity based on $16 \mathrm{~S}$ rRNA gene sequence similarity was not possible given that several different species were closely clustered, although it was clear that the two sub-Antarctic Williamsia and two Rhodococcus species were distinct from their nearest neighbours in the phylogram. Sequences for the alkB gene from type strains of R. cerastii, R. fascians and $R$. cercidiphylli were compared with this gene in Rhodococcus sp. 1163 and 1168 (Figure 3B), which confirmed that these sub-Antarctic strains formed a separate clade to the species most closely related by $16 \mathrm{~S}$ rRNA gene sequencing.

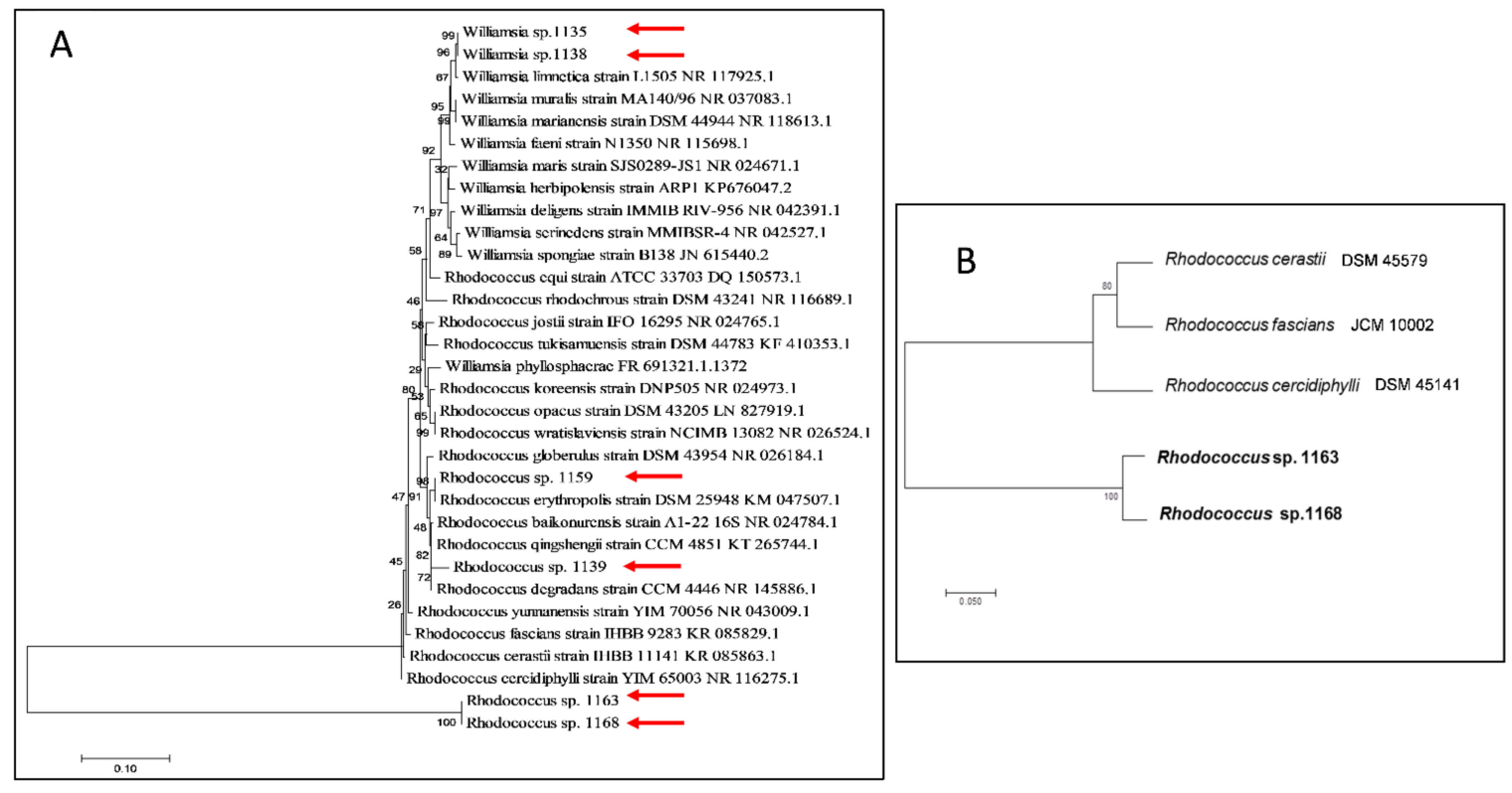

Figure 3. Neighbour-joining phylogenetic trees based on (A) BLAST analysis of 16S rRNA gene sequences obtained by PCR amplification of DNA extracted from six sub-Antarctic strains and (B) alkane 1-monooxygenase gene (alkB) gene sequences from whole genome sequences of Williamsia spp. 1135 and 1138 and Rhodococcus spp. 1139, 1159, 1163 and 1168 . Bootstrap values shown at branch nodes were based on 1000 re-samplings and the alkB gene sequences in (B) are from published genomes of the type strains for the species selected. The sub-Antarctic strains are marked with a red arrow in panel (A).

\subsection{Taxonomy of Rhodococcus Isolates Based on Analysis of Sequenced Genomes}

Figure S1 shows a phylogram based on pfam hierarchical clustering for all Rhodococcus genomes in the IMG/M database (accessed March 2020). Strain 1139 clustered with species named as $R$. erythropolis, $R$. qingshengii and $R$. baikonurensis, and 1159 clustered with strains named R. erythropolis, R. qingshengii and R. enclensis. Strains 1163 and 1168 clustered with unclassified strains and the closest neighbours were two Antarctic soil isolates, Rhodococcus spp. PAMC 28705 and PAMC 28. The latter was confirmed when a phylogenetic tree was constructed (NCBI Genome BLAST, Taxonomy Browser) for all unclassified species of Rhodococcus (Figure S2), which indicated that strains 1163 and 1168 were distinct from each other and likely represented novel species of Rhodococcus.

Pairwise ANI and AF calculations were performed to compare the sub-Antarctic rhodococci with type strains of R. erythropolis and $R$. qingshengii, as shown in the Table 3 (Part A), and the Antarctic soil isolates for strain 1163 and 1168 (Part B). Using an ANI species delimitation of $\geq 96.5 \%$ and AF of $\geq 60 \%$ [40], strain 1139 would be classified as R. qingshengii and 1159 as R. erythropolis. Strains 1163 and 1168 showed $<96.5 \%$ ANI and on that basis would be considered distinct from their nearest neighbours, the Antarctic soil strains, although AF was $>60 \%$, possibly indicating a close relationship between these species. 


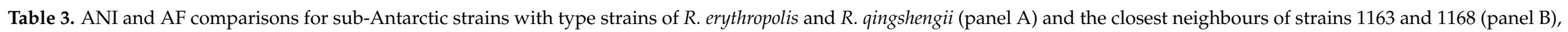
highlighting species identity between strains of R. erythropolis (orange shading) or R. qingshengii (green shading).

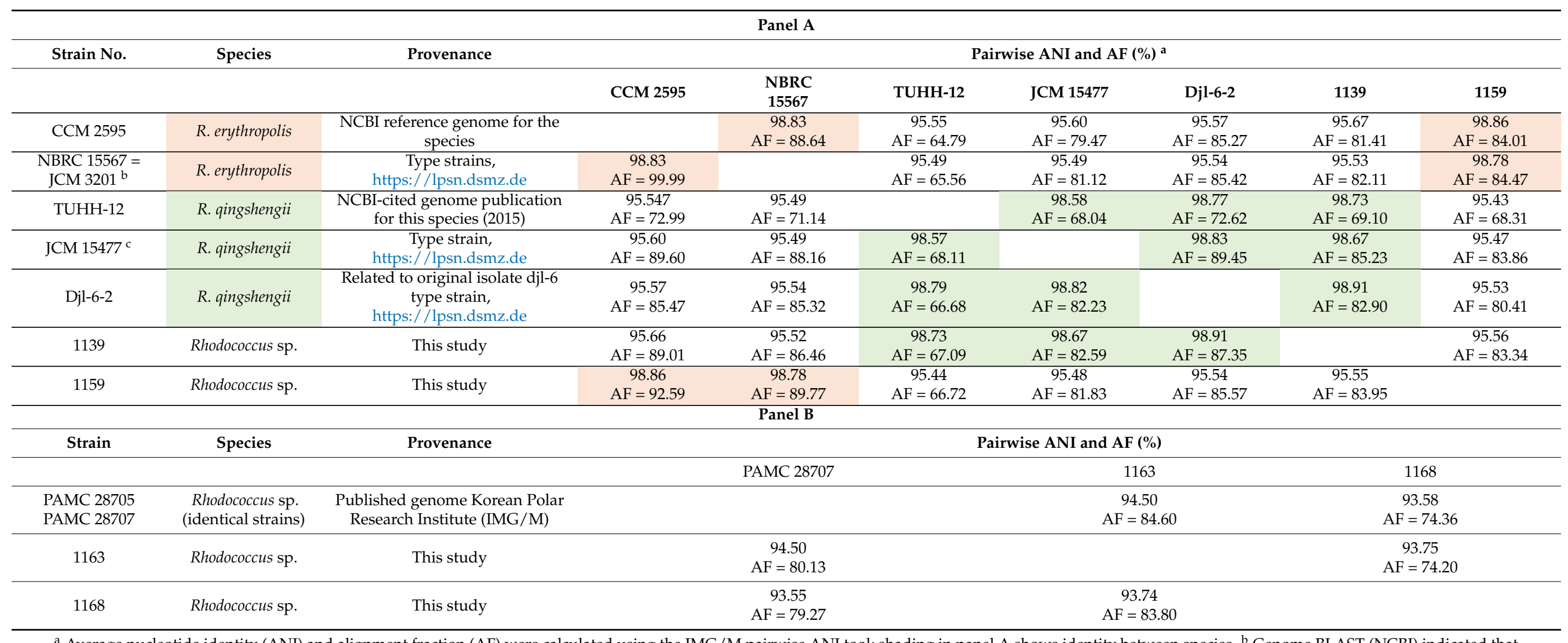

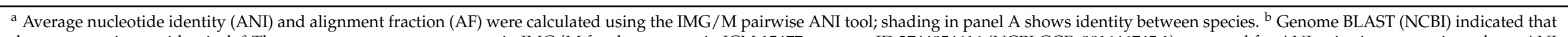

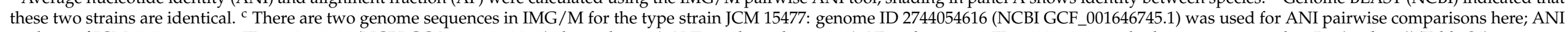
analysis of JCM 15477 genome ID 2734481946 (NCBI GCA_001313445.1) showed > 99\% ANI similarity but < 35\% AF with genome ID 2744054616 and other strains named as R. qingshengii (Table S1). 
Using the IMG/M ANI genome-clustering tool (accessed December 2020) placed strains 1139 and 1159 in clusters 401 and 420, respectively. Cluster 401 contained genomes of strains named as R. erythropolis, R. enclensis and R. qingshengii, including the type strains for $R$. qingshengii JCM 15477 (IMG/M genome ID 2744054616) and djl-6-2. Pairwise ANI comparisons of selected genomes in this clique are detailed in Table S1. There were two available genome assemblies for JCM 15477: they showed $>99 \%$ ANI similarity but $<36 \%$ AF similarity, whereas other R. qingshengii genomes showed $>98 \%$ ANI and $>89$ AF similarity, indicating detectable differences between the archived genomes of JCM 15477. Cluster 420 contains genomes for strains named as R. erythropolis, including the NCBI strain used as the reference genome for this species and type strain, CCM 2595, 1159 (which is annotated as R. erythropolis in IMG/M and NCBI databases) plus species named as $R$. opacus, $R$. rhodochrous or unclassified species. Pairwise ANI analysis between genomes in the two 'erythropolis' clusters suggests that the taxonomy of several strains currently named as R. enclensis, R. rhodochrous, R. opacus and R. baikonurensis (type strain JCM 18801) requires reconsideration, as ANI data indicate that these strains are all the same species.

\subsection{Taxonomy of Williamsia Strains Based on Mycolic Acid and Genome Sequence Analyses}

Bound and unbound mycolic acids were analysed from stationary phase cultures of strains 1135 and 1138 by UPLC-MS/MS (Table S2). Major MA components ( $>20 \%$ relative abundance) in strain 1135 contained 52-58 carbons with three double bonds and 54-58 carbons with 2 to 4 double bonds in strain 1138. MA detected under the growth conditions used for the latter stain also included components with 60 carbons and up to five double bonds in the bound MA fraction, while prior analysis of MA separated by thin layer chromatography followed by flame ionization-thermal conductivity/MS/MS showed minor components with smaller carbon chains (31-44 carbons, 0 to 5 double bonds) [41]. Multiple isomers of all MA major components were detected (Table S2).

Hierarchical clustering based on pfam functions for all Williamsia species with genomes archived in the IMG/M database (accessed May 2021) (Figure S3) showed a distinct lineage for strain 1135 while strain 1138 clustered with W. limnetica type strain, DSM 45521. Multiple sequence alignment of $16 \mathrm{~S}$ rRNA genes obtained from archived genome sequences for the three strains showed $>98.9 \%$ alignment scores, but also indicated small signature differences between these strains (Figure S4). Pairwise ANI comparisons showed 87.4 and $87.6 \%$ similarity between 1135 and 1138 to DSM 45521, respectively, and 75.7 and $79.5 \%$ AF similarity to DSM 45521, respectively. Strain 1135 showed $91.1 \%$ ANI and $78.9 \%$ AF similarity to 1138, affirming that these Williamsia strains are distinct from their nearest neighbour, DSM 45571, and from each other.

\subsection{Biochemical Characterization of the Rhodococcus Strains 1139 and 1159}

Given that Rhodococcus strains 1139 and 1159 clustered with mesophilic Rhodococcus strains which included species described as heterotypic synonyms, further biochemical analyses were undertaken to determine whether these strains displayed differentiating traits, considering their origin on Macquarie Island (with oceanic geology, exposure to sea-spray and sub-Antarctic temperatures [42]).

\subsubsection{Enzymatic Characterization of Bacterial Strains and Carbon Source Utilization}

The API ZYM test showed Rhodococcus sp. 1139 and 1159 were both strongly positive for leucine arylamidase, alkaline phosphatase, acid phosphatase, esterase lipase (C8), $\alpha$ glucosidase and $\beta$-glucosidase, and showed weaker but detectable activity for esterase (C4), lipase, valine acrylamidase, cystine arylamidase, $\alpha$-chymotrypsin and napthanolAS-Bl-phosphohydrolase (Table S4). Examination of the genomes detected all genes in the ureide pathway for breakdown of nucleosides, including urease, although this was not experimentally tested here. Both strains showed similar $\mu_{\max }$ on MSM-F and grew on glycerol. Growth rate on D-glucose in MSM was low but supplementing MSM-glucose 
with yeast extract increased this 3-4-fold for both strains. However, the highest $\mu_{\max }$ was found on $D$-sorbitol and $D$-fructose for both strains (Figure S5).

3.7.2. Identifying Preferred Nitrogen Sources and Impact of Phosphate Ion Concentration

Rhodococcus sp. 1139 and 1159 were initially screened in MSM-F media with the normally-used nitrogen source, $\mathrm{NH}_{4} \mathrm{H}_{2} \mathrm{PO}_{4}(\mathrm{AP})$, replaced with different potential nitrogen sources (urea and sulphate counter-ion with ammonium and nitrate), and combinations of these (Figure S6). Both strains could utilize ammonium, nitrate and urea as nitrogen sources to varying degrees.

When the phosphate ion concentration was adjusted to account for the decrease in total phosphate when $\mathrm{NH}_{4} \mathrm{H}_{2} \mathrm{PO}_{4}$ was replaced (phosphate-adjusted MSM-F media, $-\mathrm{P}$ ), providing $25 \%$ more phosphate ion, both strains showed significant differences in $\mu_{\max }$ and maximum final $\mathrm{OD}_{600}$ for all the nitrogen sources. Growth on ammonium sulphate (AS) was higher than AP when both were supplemented at $2 \mathrm{~g} / \mathrm{L}$, reflecting the higher concentration of nitrogen in AS; the higher concentration of phosphate in AS-P further improved growth.

\subsubsection{Salt Tolerance}

Rhodococcus sp. 1139 and 1159 were cultured in MSM-F broths supplemented with 1 to $15 \% \mathrm{NaCl}$. Both Rhodococcus strains, 1139 and 1159 , could tolerate up to $7 \% \mathrm{NaCl}$.

\subsubsection{Strains 1139 and 1159 Are Psychrotolerant and Predicted to Survive at Sub-Zero} Temperatures

Bacterial strains were cultured in MSM-F at temperatures between 0 to $45{ }^{\circ} \mathrm{C}$ to determine the temperature for fastest growth rate $\left(\mathrm{T}_{\mathrm{opt}}\right)$ (Figure S7a). The experimentallydetermined temperature range for growth was 0 to $35^{\circ} \mathrm{C}$ with fastest growth rate at $30{ }^{\circ} \mathrm{C}$ for both 1139 and 1159. It was determined from the nonlinear model that these strains were predicted to survive at very low temperatures; the $\mathrm{T}_{\min }$ was calculated as $-9.5 \pm 1.4$ and $-12 \pm 0.8^{\circ} \mathrm{C}$ and $\mathrm{T}_{\max }$ as $35.3 \pm 2.5$ and $37.5 \pm 0.5^{\circ} \mathrm{C}$, respectively, which is in good agreement with the measured growth ranges (Table S5). One example of the nonlinear fitted model is shown in Figure S7b.

\subsubsection{MA Analysis by UPLC-MS/MS}

Table S6 summarizes the ESI-MS profiles for the major bound and unbound MA detected in the sub-Antarctic Rhodococcus strains. The MA found in Rhodococcus strains 1139 and 1159 had a wide range of carbon chain lengths, ranging from 34 to 58 with up to five double bonds. The major bound MA components had 36 to 46 carbons and one or two double bonds and tandem quadrupole MS data revealed 2-4 isomers for the major molecular species. The $\alpha$-branch of these Rhodococcus strains ranged from 10 to 19 carbons with 0 to 1 double bonds and the meromycolate branch ranged from 24 to 44 carbons with 0 to 5 double bonds. The major bound MA in Rhodococcus spp. 1163 and 1168 contained 44-48 carbons, mainly with one or two double bonds, and longer-chained MA (up to 54 carbons) were detected as minor (relative abundance 20-62\%) components, differentiating these novel species from 1139 and 1159. Strain 1163 also had a higher proportion of larger MA $(50: 2,58: 4)$ in the unbound fraction.

\subsubsection{TAG Analysis by UPLC-MS/MS}

TAG molecular species eluted from the UPLC column between 6.6 and $9.5 \mathrm{~min}$. TAGs were partially resolved into broad peaks consisting of several individual TAG molecular species. Mass spectra of these regions were averaged to determine the types of TAG present as $\left[\mathrm{M}+\mathrm{NH}_{4}\right]^{+}$and $[\mathrm{M}+\mathrm{Na}]^{+}$adduct ions (Table S7). ESI-MS profiles of carbon units in TAG of Rhodococcus strains ranged from 46 to 52 with 1 to 3 double bonds. 


\subsubsection{FAME Analysis by GC-MS}

The carbon chain length of fatty acids (FA) ranged from 12 to 22 with up to one double bond in both Rhodococcus strains (Table S8). The major FA detected were $\mathrm{C}_{16: 0}(31.2 \%)$, $\mathrm{C}_{18: 1}(20.2 \%)$ and 10-methyl $\mathrm{C}_{18: 0}(21.2 \%)$. Other minor FAs detected included $\mathrm{C}_{16: 1}$ (two isomers, $10.4 \%), \mathrm{C}_{14: 0}(5.3 \%), \mathrm{C}_{18: 0}(2.2 \%)$ and very minor relative proportions $(<2 \%)$ of longer-chained $\left(\mathrm{C}_{19: 1}-\mathrm{C}_{22: 1}\right)$ and branched-chained FA.

\section{Discussion}

Genome-based taxonomic classification of bacteria is being applied increasingly, in parallel with developing standards for defining the lineages in several phyla and genera, including the Actinobacteria $[25,43,44]$. Sequence quality depends on several parameters, including the suitability of the DNA provided to meet criteria for use in next-generation sequencing, particularly providing templates for long reads for high-fidelity genome assembly and determining GC content [45]; selecting appropriate methodologies for DNA preparation is a crucial factor in phylogenomics. There are several commercial gDNA extraction kits available which have been successfully used for genome sequencing of Actinobacteria and mycolate-containing Corynebacteriales strains, as demonstrated by the increasing number of Rhodococcus and other genomes archived in the NCBI Genome Assembly database. Genome assembly quality underpins nomenclature and taxonomy when identifying species clusters through ANI comparisons with type strains, as employed as one of the tools in the Genome Taxonomy Database (GTDB) [46]. This is exemplified by reviewing the current number of Rhodococcus assemblies examined in the GTDB, where 20 of 384 assemblies (accessed December 2020) failed the quality check using CheckM [47], based on completeness, contamination or strain heterogeneity. Consequently, these 20 examples of both named and unclassified Rhodococcus spp. could not be assigned to any species cluster. It was also noted here that the two archived genome sequences for the type strain of R. qingshengii JCM 15477 showed different AF values, which may indicate that caution is required when selecting a 'type strain' genome assembly for comparative taxonomic purposes.

We were able to shotgun sequence six unclassified sub-Antarctic Corynebacteriales strains [27-29] after optimizing gDNA extraction using a method based on those described by Marmur [14,15]. This method was only successful when the strains were cultured in broths containing concentrations of glycine that were highly growth-inhibitory, which predisposed cells to lysozyme and proteinase $\mathrm{K}$ digestion. We assessed the quality of the gDNA using fragment size and size distribution data (Fragment Analyser, GQN) plus protein/DNA and RNA/DNA ratios, in addition to data provided by Macrogen Inc during sequencing (Q30, phred quality score) and after assembly using ABySS software (N50, L50, number of contigs and GC content) (see Table 2). The assemblies for all six strains passed CheckM in the GTDB and were assigned to species clusters, affirming the quality of the gDNA used to explore their taxonomic position and the phylogeny described herein.

Some bacteria are highly or moderately sensitive to growth inhibition by glycine, while others are resistant; there is no conclusive relationship between the sensitivity and bacterial physiological properties such as their Gram staining status, morphology or aerobic and anaerobic nature [48]. Sensitivity to growth inhibition also varies among bacterial species and strains, not with genus [20]. In this study, all the Corynebacteriales strains were moderately resistant to lower concentrations of glycine. However, Williamsia sp. 1135 was more sensitive to higher concentrations of glycine than Williamsia sp. 1138. Similar observations were previously reported for Corynebacterium species [19], where C. mediolanum was completely inhibited by $1.25 \%$ glycine, whereas $C$. insidiosum was similarly inhibited by $0.8 \%$ glycine. This demonstrates the need to evaluate each strain for the inhibitory effects of glycine prior to cultivation for DNA extraction if difficulties arise in using kits or other wet-lab procedures for cell lysis.

The results show that higher concentrations of glycine (4.0-4.5\%) in the culture media facilitated enzymatic cell disruption of the sub-Antarctic strains, increasing the DNA 
yield for both the classical extraction method and commercial kit methods. A longer incubation period was required to disrupt cells grown in 0 and $2 \%$ MSM-G and the strains showed variability in the incubation time required to achieve visible lysis (notably the novel species of Rhodococcus, 1163 and 1168 required longer enzymatic treatment than the other Rhodococcus species, even after growth in $4.5 \%$ glycine). The need to optimize enzyme treatment periods was noted previously for kit-based extraction of DNA from actinobacterial cells not cultured in glycine-enriched media $[17,18,49]$. Williamsia sp. 1138, selected for optimizing gDNA extraction methods, was particularly recalcitrant to lysis. The size range of MA molecules detected in both sub-Antarctic Williamsia strains was in line with publications defining the novel genus (50-56 carbons) [50] and W. limnetica (50-58 carbons) [51], the closest neighbour phylogenetically. Under the growth conditions used, Williamsia sp. 1138 showed a higher size range of MA than the rhodococci, up to 60 carbons and multiple double bonds, which may contribute to the difficulty in cell lysis during gDNA extraction. Williamsia species are more rarely detected in environmental samples assessed following community DNA extraction, despite occupying similar ecological niches to Rhodococcus species; greater difficulty in cell lysis may contribute to these observations. The cell surface structures of Rhodococcus species vary within the genus, with some displaying relatively shorter MA (28-46 carbons) and others with longer chains (34-54 carbons) [52], in addition to a range of complex covalently-bound and unbound lipid plus carbohydrate structures [53]. The novel Rhodococcus spp., 1163 and 1168, contained a higher proportion of longer-chained MA (50-54 carbons) (Table S6) which may also have contributed to their resistance to lysis by enzymatic treatments, again emphasizing the need for optimizing gDNA extraction protocols for phylogenomic purposes when handling new species.

Although 16S rRNA gene sequencing is commonly used to determine phylogenomic relationships between bacterial strains, it is considered a poor predictor of proteome similarity [40] and was unable to resolve some genera and species in the phylum Actinobacteria [25]. While other genes, such as $r p o B$ or groups of genes used in multi-locus sequence typing, may be better predictors, genome-wide measures of similarity, ANI and AF, strongly correlated with proteome similarity in Streptomyces and Bacillus without limiting analyses to the core genomes to eliminate input from genes recently acquired from horizontal transfer [40]. Neighbour-joining phylogenetic trees based on 16S rRNA genes, and alkB for strains 1163 and 1168, plus ANI-based whole-genome sequence cluster analyses, clearly indicated that the two Williamsia strains 1135 and 1138 and the Rhodococcus strains 1163 and 1168 are likely novel species, as they formed distinct clades. In contrast, Rhodococcus strains 1139 was phylogenetically close to R. qingshengii and 1159 to R. erythropolis, based on $16 \mathrm{~S}$ rRNA gene sequences, ANI analyses and phylogenetic trees based on pfam or COG clustering. However, Rhodococcus sp. 1139 was also phylogenetically and biochemically closely related to $R$. degradans (see Table S9, which summarizes the biochemical and genetic traits of strains 1139 and 1159 together with published data for type strains of $R$. degradans, $R$. qingshengii and R. erythropolis). Following the original description of R. erythropolis in 1977 [54] as a member of the genus Rhodococcus (formerly Nocardia), it has become increasingly recognized that several validly published species of Rhodococcus are closely related to R. erythropolis and are members of the 'erythropolis/qingshengii/enclensis' group. The original description of $R$. degradans (CCM $4446=$ HA1) as a distinct species [23] was based on several standard parameters, including $16 \mathrm{~S}$ rRNA, gyr $A$ and cat $A$ sequence comparisons, ribotyping, protein fingerprinting and DNA-DNA hybridisation. The authors noted that this proposed new species was phylogenetically related to $R$. globerulus, $R$. baikonurensis, $R$. qingshengii and $R$. erythropolis (the ' $16 \mathrm{~S}$ rRNA gene clade') but was differentiated based on carbon source usage. However, it was also noted that there were several disparities between carbohydrate utilisation tests when using kits and test-tube cultures. Our data for growth on different carbon and nitrogen sources was based on measuring the maximum growth rates and extent of growth, providing a stronger experimental platform for determining carbon source usage. Furthermore, the basal medium formulation (counter-ions for nitrogen sources, level of phosphate and presence of yeast 
extract in the MSM) impacted on the growth rates on some carbon sources, suggesting that strain differentiation based on carbon source utilization patterns is problematic given that outcomes depend on methodology and media used. These observations also indicated that any subsequent media optimization for biomass yield and TAG synthesis would need to evaluate the ratio of nitrogen, phosphate and sulphate ion concentrations in addition to the ratio of carbohydrate to nitrogen, which is considered a critical factor in TAG synthesis [7]. Table S9 shows that there are few biochemical traits which can differentiate between $R$. erythropolis, $R$. qingshengii and $R$. degradan, and between the type strains of these species and sub-Antarctic strains 1139 and 1159. The possible exceptions are higher salt tolerance and lowest minimum growth temperature, although it is difficult to be conclusive given that our data was based on longer incubation periods (up to 4 months for growth temperature experiments) relative to the methods used when describing the relevant type cultures. The genome for strain DSM 6344 (described as R. erythropolis = HA1 in the German culture collection and $R$. degradans for the equivalent strain in the Belgium collection, LMG $28633=$ HA1) is now available (GenBank assembly accession GCA_009863335.1) [24]. Lee et al. [24] noted that $R$. degradans is a later heterotypic synonym of $R$. qingshengii [55], adding to the prior publications indicating that $R$. jialingiae [26] and $R$. enclensis [25] are also later heterotypic synonyms of $R$. qingshengii. Using a species delineation ANI point of $98 \%$, and > $60 \%$ AF, proved useful in classifying the sub-Antarctic Rhodococcus species, which is higher than the typically used point of 95\% (see [45]); using 95\% would place all of these named species into one. While further taxonomic tools will likely emerge to assess phylogenetic relationships between closely related bacteria, rationalisation of the nomenclature within the 'erythropolis' group may provide greater clarity in two areas: establishing claims of novel biotechnological prowess of new isolates; and tracking fundamental research on the biochemical and regulation systems in this group.

\section{Conclusions}

Prior culture in media supplemented with growth-inhibitory concentrations of glycine improved cell lysis for six lysozyme-resistant sub-Antarctic Rhodococcus and Williamsia isolates, using a classical method for gDNA extraction. Two extraction kits also yielded gDNA with fragment sizes suitable for third-generation sequencing. However, one kit only produced high-quality yields of DNA from E. coli, while the fragment size distribution for gDNA from the sub-Antarctic strains failed quality evaluation for genomic sequencing, although it was adequate for PCR amplification of 16S rRNA genes. Phylogenetic analysis of the sequenced genomes indicated that four sub-Antarctic strains are novel species which contained longer-chained mycolic acids, which may have contributed to their resistance to lysis. Two strains were classified as known species of Rhodococcus, which displayed biochemical traits expected of R. qingshengii (1139) and R. erythropolis (1159) and were both psychrotrophic. ANI clustering and further pairwise analyses indicated that delineation points of ANI similarity $>96.5 \%$ and AF $>60 \%$ were useful in classifying strains 1139 and 1159. However, ANI similarity of $>98 \%$ was required to differentiate between strains in two ANI genome clusters which included $R$. erythropolis and $R$. qingshengii type strains. Several strains in these two clusters are currently named as $R$. enclensis, R. baikonurensis, $R$. opacus and other Rhodococcus species, indicating that the taxonomic position of these strains in the R. erythropolis group requires clarification.

Supplementary Materials: The following are available online at https:/ / www.mdpi.com/article/ 10.3390/microorganisms9061253/s1. Figure S1: Hierarchical clustering based on pfam functions of all Rhodococcus species with genomes archived in the IMG/M database (accessed March, 2020); Figure S2: Phylogenetic tree for all unclassified species of Rhodococcus (constructed using NCBI Genome BLAST, Taxonomy Browser); Figure S3: Hierarchical clustering based on pfam functions of all Williamsia species with genomes archived in the IMG/M database (accessed May, 2021); Figure S4: Multiple sequence alignment (Clustal 2.1) of 16S rRNA genes from the genome sequences of Williamsia sp. 1135 and 1138 and Williamsia limnetica (DSM 45521 ${ }^{\mathrm{T}}$ ) archived in the IMG/M database (accessed February 2021); Figure S5: Maximum growth rates $\left(\mu_{\max }, \mathrm{h}^{-1}\right)$ and final $\mathrm{OD}_{600}$ on different 
carbon sources of bacterial strains: (a) Rhodococcus sp. 1139 and (b) Rhodococcus sp. 1159; Figure S6: Maximum growth rates $\left(\mu_{\max }, \mathrm{h}^{-1}\right)$ and final $\mathrm{OD}_{600}$ on different nitrogen sources of bacterial strains: (a) Rhodococcus sp. 1139 and (b) Rhodococcus sp. 1159; Figure S7: Impact of temperature on growth kinetics of Rhodococcus strain 1139 and 1159. (a) Maximum growth rates $\left(\mu_{\max }, \mathrm{h}^{-1}\right)$ at different temperatures during culture in MSM-F broth; (b) one example of the nonlinear fitted model for strain 1159; Table S1: ANI and AF pairwise comparison of sub-Antarctic Rhodococcus isolates with other Rhodococcus strains selected from ANI genome clusters containing species in the R. erythropolis group ('erythropolis/qingshengii/enclensis') available at the IMG/M site (accessed in March 2020); Table S2: Mycolic acids (relative abundance $\geq 20 \%$ ) of Williamsia spp. 1135 and 1138; Table S3: ANI and AF pairwise comparison of sub-Antarctic Williamsia isolates 1135 and 1138 with other Williamsia species for genomes available at the IMG/M site (accessed in May 2021); Table S4: Enzymatic characteristics of Rhodococcus strains 1139 and 1159; Table S5: Experimentally determined and modelled temperature profiles of Rhodococcus strains 1139 and 1159; Table S6: Mycolic acids (relative abundance $\geq 20 \%$ ) of sub-Antarctic Rhodococcus strains; Table S7: Major triacylglycerols found in Rhodococcus strains 1139 and 1159; Table S8: Total fatty acids composition of Rhodococcus strains 1139 and 1159; Table S9: Phenotypic and genotypic characteristics of Rhodococcus strains 1139 and 1159 and closely related type strains.

Author Contributions: Conceptualization, M.L.B.; Data curation, A.N. and D.S.N.; Formal analysis, A.N., D.S.N. and M.L.B.; Funding acquisition, M.L.B.; Investigation, A.N.; Methodology, A.N., A.L.B. and D.S.N.; Project administration, A.L.B., J.P.B. and M.L.B.; Resources, J.P.B. and M.L.B.; Software, D.S.N.; Supervision, A.L.B., D.S.N., J.P.B. and M.L.B.; Validation, A.N.; Writing-original draft, A.N.; Writing-review and editing, A.L.B., D.S.N., J.P.B. and M.L.B. All authors have read and agreed to the published version of the manuscript.

Funding: This research received no external funding.

Institutional Review Board Statement: Not applicable.

Informed Consent Statement: Not applicable.

Acknowledgments: We would like to thank Michael Charleston from the School of Natural Sciences, University of Tasmania (Australia), for helping to assemble the bacterial genomes using ABySS software and Ross Corkrey from the Tasmanian Institute of Agriculture, University of Tasmania (Australia), for assisting to predict the bacterial growth temperature ranges using a nonlinear model. Akhikun Nahar's PhD project was funded by an Endeavour Postgraduate Scholarship (Australian Government Colombo Plan) and operating costs from the office of the Dean of Science, Engineering and Technology.

Conflicts of Interest: The authors declare no conflict of interest.

\section{References}

1. Mayjonade, B.; Gouzy, J.; Donnadieu, C.; Pouilly, N.; Marande, W.; Callot, C.; Langlade, N.; Muños, S. Extraction of highmolecular-weight genomic DNA for long-read sequencing of single molecules. Biotechniques 2016, 61, 203-205. [CrossRef] [PubMed]

2. Buermans, H.; Den Dunnen, J. Next generation sequencing technology: Advances and applications. Biochim. Biophys. Acta Mol. Basis Dis. 2014, 1842, 1932-1941. [CrossRef] [PubMed]

3. Healey, A.; Furtado, A.; Cooper, T.; Henry, R.J. Protocol: A simple method for extracting next-generation sequencing quality genomic DNA from recalcitrant plant species. Plant Methods 2014, 10, 21. [CrossRef]

4. Kitagawa, W.; Kimura, N.; Kamagata, Y. A novel p-nitrophenol degradation gene cluster from a gram-positive bacterium, Rhodococcus opacus SAO101. J. Bacteriol. 2004, 186, 4894-4902. [CrossRef] [PubMed]

5. Sun, J.-Q.; Xu, L.; Tang, Y.-Q.; Chen, F.-M.; Liu, W.-Q.; Wu, X.-L. Degradation of pyridine by one Rhodococcus strain in the presence of chromium (VI) or phenol. J. Hazard. Mater. 2011, 191, 62-68. [CrossRef]

6. Inoue, D.; Tsunoda, T.; Yamamoto, N.; Ike, M.; Sei, K. 1, 4-Dioxane degradation characteristics of Rhodococcus aetherivorans JCM 14343. Biodegradation 2018, 29, 301-310. [CrossRef] [PubMed]

7. Alvarez, H.; Steinbüchel, A. Triacylglycerols in prokaryotic microorganisms. Appl. Microbiol. Biotechnol. 2002, 60, 367-376. [CrossRef] [PubMed]

8. Holder, J.W.; Ulrich, J.C.; DeBono, A.C.; Godfrey, P.A.; Desjardins, C.A.; Zucker, J.; Zeng, Q.; Leach, A.L.; Ghiviriga, I.; Dancel, C. Comparative and functional genomics of Rhodococcus opacus PD630 for biofuels development. PLoS Genet. 2011, 7, e1002219. [CrossRef] 
9. Shavandi, M.; Mohebali, G.; Haddadi, A.; Shakarami, H.; Nuhi, A. Emulsification potential of a newly isolated biosurfactantproducing bacterium, Rhodococcus sp. strain TA6. Colloids Surf. B. Biointerfaces 2011, 82, 477-482. [CrossRef]

10. Dhakal, D.; Shrestha, A.; Thuan, N.H.; Rayamajhi, V.; Mishra, R.; Magar, R.T.; Sohng, J.K. Bioactive Compounds from Nocardia: Biosynthesis and Production. In Pharmaceuticals from Microbes; Arora, D., Sharma, C., Jaglan, S., Lichtfouse, E., Eds.; Springer: Cham, Switzerland, 2019; Volume 28, pp. 49-74. [CrossRef]

11. Mischitz, M.; Faber, K.; Willetts, A. Isolation of a highly enantioselective epoxide hydrolase from Rhodococcus sp. NCIMB 11216. Biotechnol. Lett. 1995, 17, 893-898. [CrossRef]

12. Hébert, L.; Bidaud, P.; Goux, D.; Benachour, A.; Laugier, C.; Petry, S. Study of lysozyme resistance in Rhodococcus equi. Curr. Microbiol. 2014, 68, 352-357. [CrossRef]

13. Amaro, A.; Duarte, E.; Amado, A.; Ferronha, H.; Botelho, A. Comparison of three DNA extraction methods for Mycobacterium bovis, Mycobacterium tuberculosis and Mycobacterium avium subsp. avium. Lett. Appl. Microbiol. 2008, 47, 8-11. [CrossRef]

14. Marmur, J.A. Procedure for the isolation of deoxyribonucleic acid from microorganisms. J. Mol. Biol. 1961, 3, 201-218. [CrossRef]

15. Sambrook, J.; Fritsch, E.F.; Maniatis, T. Molecular Cloning: A Laboratory Manual; Cold Spring Harbor Laboratory Press: New York, NY, USA, 1989; ISBN 0879693096.

16. Wu, G.D.; Lewis, J.D.; Hoffmann, C.; Chen, Y.-Y.; Knight, R.; Bittinger, K.; Hwang, J.; Chen, J.; Berkowsky, R.; Nessel, L. Sampling and pyrosequencing methods for characterizing bacterial communities in the human gut using 16S sequence tags. BMC Microbiol. 2010, 10, 206. [CrossRef] [PubMed]

17. Gontang, E.A.; Fenical, W.; Jensen, P.R. Phylogenetic diversity of gram-positive bacteria cultured from marine sediments. Appl. Environ. Microbiol. 2007, 73, 3272-3282. [CrossRef] [PubMed]

18. Schorn, M.A.; Alanjary, M.M.; Aguinaldo, K.; Korobeynikov, A.; Podell, S.; Patin, N.; Lincecum, T.; Jensen, P.R.; Ziemert, N.; Moore, B.S. Sequencing rare marine actinomycete genomes reveals high density of unique natural product biosynthetic gene clusters. Microbiology 2016, 162, 2075-2086. [CrossRef]

19. Hammes, W.; Schleifer, K.; Kandler, O. Mode of action of glycine on the biosynthesis of peptidoglycan. J. Bacteriol. 1973, 116, 1029-1053. [CrossRef]

20. Sato, H.; Diena, B.; Greenberg, L. The production of spheroplasts by rapid-growing non-virulent mycobacteria. Can. J. Microbiol. 1965, 11, 807-810. [CrossRef]

21. Haynes, J.A.; Britz, M.L. The effect of growth conditions of Corynebacterium glutamicum on the transformation frequency obtained by electroporation. Microbiology 1990, 136, 255-263. [CrossRef]

22. Chun, J.; Oren, A.; Ventosa, A.; Christensen, H.; Arahal, D.R.; da Costa, M.S.; Rooney, A.P.; Yi, H.; Xu, X.-W.; De Meyer, S. Proposed minimal standards for the use of genome data for the taxonomy of prokaryotes. Int. J. Syst. Evol. Microbiol. 2018, 68, 461-466. [CrossRef]

23. Švec, P.; Černohlávková, J.; Busse, H.-J.; Vojtková, H.; Pantu, R.; Cnockaert, M.; Mašlaňová, I.; Králová, S.; Vandamme, P.; Sedláček, I. Classification of strain CCM 4446T as Rhodococcus degradans sp. nov. Int. J. Syst. Evol. Microbiol. 2015, 65, 4381-4387. [CrossRef] [PubMed]

24. Lee, S.D.; Kim, I.S.; Kim, Y.J.; Young, Y. Rhodococcus cavernicola sp. nov., isolated from a cave, and Rhodococcus degradans is a later heterosynonym of Rhodococcus qingshengii. Int. J. Syst. Evol. Microbiol. 2020, 70, 4409-4415. [CrossRef] [PubMed]

25. Nouioui, I.; Carro, L.; García-López, M.; Meier-Kolthoff, J.; Woyke, T.; Kyrpides, N.; Klenk, H.-P.; Goodfellow, M.; Göker, M. Genome-based taxonomic classification of the phylum Actinobacteria. Front. Microbiol. 2018, 9, 2007. [CrossRef] [PubMed]

26. Táncsics, A.; Benedek, T.; Farkas, M.; Máthé, I.; Márialigeti, K.; Szoboszlay, S.; Kukolya, J.; Kriszt, B. Sequence analysis of 16S rRNA, gyrB and catA genes and DNA-DNA hybridization reveal that Rhodococcus jialingiae is a later synonym of Rhodococcus qingshengii. Int. J. Syst. Evol. Microbiol. 2014, 64, 298-301. [CrossRef]

27. Nahar, A.; Baker, A.L.; Charleston, M.A.; Bowman, J.P.; Britz, M.L. Draft genome sequences of three sub-Antarctic Rhodococcus spp., including two movel psychrophilic genomospecies. Microbiol. Resour. Announc. 2017, 5, e00898-17. [CrossRef]

28. Nahar, A.; Baker, A.L.; Charleston, M.A.; Bowman, J.P.; Britz, M.L. Draft genome sequences of two novel sub-Antarctic Williamsia species. Microbiol. Resour. Announc. 2017, 5, e01047-17. [CrossRef] [PubMed]

29. Nahar, A.; Baker, A.L.; Charleston, M.A.; Britz, M.L. Draft genome sequence of subantarctic Rhodococcus sp. strain 1139. Microbiol. Resour. Announc. 2017, 5, e00090-17. [CrossRef]

30. Monod, J. The growth of bacterial cultures. Ann. Rev. Microbiol. 1949, 3, 371-394. [CrossRef]

31. Hall, T.A. BioEdit: A user-friendly biological sequence alignment editor and analysis program for Windows 95/98/NT. Nucleic Acids Symp. Ser. 1999, 41, 95-98.

32. Chen, I.-M.A.; Chu, K.; Palaniappan, K.; Pillay, M.; Ratner, A.; Huang, J.; Huntemann, M.; Varghese, N.; White, J.R.; Seshadri, R. IMG/M v. 5.0: An integrated data management and comparative analysis system for microbial genomes and microbiomes. Nucleic Acids Res. 2018, 47, D666-D677. [CrossRef] [PubMed]

33. Lincoln, S.A.; Hamilton, T.L.; Juárez, A.G.V.; Schedler, M.; Macalady, J.L.; Müller, R.; Freeman, K.H. Draft genome sequence of the piezotolerant and crude oil-degrading bacterium Rhodococcus qingshengii strain TUHH-12. Microbiol. Resour. Announc. 2015, 3, e00268-15. [CrossRef]

34. Parte, A.C. LPSN-List of prokaryotic names with standing in nomenclature (bacterio. net), 20 years on. Int. J. Syst. Evol. Microbiol. 2018, 68, 1825-1829. [CrossRef] [PubMed] 
35. Kumar, S.; Stecher, G.; Tamura, K. MEGA7: Molecular Evolutionary Genetics Analysis version 7.0 for bigger datasets. Mol. Biol. Evol. 2016, msw054. [CrossRef]

36. Táncsics, A.; Benedek, T.; Szoboszlay, S.; Veres, P.G.; Farkas, M.; Máthé, I.; Márialigeti, K.; Kukolya, J.; Lányi, S.; Kriszt, B. The detection and phylogenetic analysis of the alkane 1-monooxygenase gene of members of the genus Rhodococcus. Syst. Appl. Microbiol. 2015, 38, 1-7. [CrossRef]

37. Ratkowsky, D.; Olley, J.; McMeekin, T.; Ball, A. Relationship between temperature and growth rate of bacterial cultures. J. Bacteriol. 1982, 149, 1-5. [CrossRef]

38. Elzhov, T.V.; Mullen, K.M.; Spiess, A.-N.; Bolker, B.; Mullen, M.K.M.; Suggests, M. Package 'minpack.lm'. 2016. Available online: https://rdocumentation.org/packages/minpack.lm/versions/1.2-1 (accessed on 1 December 2018).

39. McLean, S.; Davies, N.W.; Nichols, D.S.; Mcleod, B.J. Triacylglycerol estolides, a new class of mammalian lipids, in the paracloacal gland of the brushtail possum (Trichosurus vulpecula). Lipids 2015, 50, 591-604. [CrossRef]

40. Wright, E.S.; Baum, D.A. Exclusivity offers a sound yet practical species criterion for bacteria despite abundant gene flow. BMC Genom. 2018, 19, 724. [CrossRef]

41. Nahar, A.; Baker, A.L.; Nichols, D.S.; Bowman, J.P.; Britz, M.L. Application of thin-layer chromatography-flame ionization detection (TLC-FID) to total lipid quantitation in mycolic-acid synthesizing Rhodococcus and Williamsia species. Int. J. Mol. Sci. 2020, 21, 1670. [CrossRef] [PubMed]

42. Australian Government, Department of Agriculture, Water and the Environment, World Heritage Places, Macquarie Island. Available online: Htpp:/ / environment.gov.au/heritage/places/world/Macquarie-island (accessed on 20 May 2021).

43. Sangal, V.; Goodfellow, M.; Jones, A.L.; Schwalbe, E.C.; Blom, J.; Hoskisson, P.A.; Sutcliffe, I.C. Next-generation systematics: An innovative approach to resolve the structure of complex prokaryotic taxa. Sci. Rep. 2016, 6, 38392. [CrossRef] [PubMed]

44. Baek, I.; Kim, M.; Lee, I.; Na, S.-I.; Goodfellow, M.; Chun, J. Phylogeny trumps chemotaxonomy: A case study involving Turicella otitidis. Front. Microbiol. 2018, 9, 834. [CrossRef]

45. Tyler, A.D.; Christianson, S.; Knox, N.C.; Mabon, P.; Wolfe, J.; Van Domselaar, G.; Graham, M.R.; Sharma, M.K. Comparison of sample preparation methods used for the next-generation sequencing of Mycobacterium tuberculosis. PLoS ONE 2016, 11, e0148676. [CrossRef] [PubMed]

46. Parks, D.H.; Chuvochina, M.; Chaumeil, P.A.; Rike, C.; Mussig, A.J.; Hugenholtz, P. A complete domain-to-species taxonomy for Bacteria and Archaea. Nat. Biotechnol. 2020, 38, 1079-1086. [CrossRef]

47. Parks, D.H.; Imelfort, M.; Skennerton, C.T.; Hugenholtz, P.; Tyson, G.W. CheckM: Assessing the quality of microbial genomes recovered from isolates, single cells, and metagenomes. Genome Res. 2015, 25, 1043-1055. [CrossRef]

48. Hishinuma, F.; Izaki, K.; Takahashi, H. Effects of glycine and D-amino acids on growth of various microorganisms. Agric. Biol. Chem. 1969, 33, 1577-1586. [CrossRef]

49. Lechevalier, M.; Prauser, H.; Labeda, D.; Ruan, J.-S. 2 new genera of nocardioform actinomycetes: Amycolata gen. nov. and Amycolatopsis gen. nov. Int. J. Syst. Evol. Microbiol. 1986, 36, 29-37. [CrossRef]

50. Kampfer, P.; Anderson, M.A.; Raine, F.A.; Kroppenstedt, R.M.; Salkinoja-Salonen, M. Williamsia muralis gen. nov., sp. nov., isolated from the indoor environment of a children's day care centre. Int. J. Syst. Bacteriol. 1999, 49, 681-687. [CrossRef]

51. Sazak, A.; Sahin, N. Williamsia limnetica sp. nov., isolated from a limnetic lake sediment. Int. J. Syst. Evol. Microbiol. 2012, 62, 1414-1418. [CrossRef] [PubMed]

52. Sutcliffe, I.C. Cell envelope composition and organisation in the genus Rhodococcus. Antonie Van Leeuwenhoek 1998, 74, 49-58. [CrossRef] [PubMed]

53. Sutcliffe, I.C.; Brown, A.K.; Dover, L.G. The rhodococcal cell envelope: Composition, organisation and biosynthesis. In Biology of Rhodococcus; Microbiology Monographs 16; Alvarez, H.M., Ed.; Springer: Berlin/Heidelberg, Germany, 2010; pp. 30-71. [CrossRef]

54. Goodfellow, M.; Alderson, G. The Actinomycete-genus Rhodococcus: Home for the 'rhodochrous' complex. J. Gen. Microbiol. 1977, 100, 99-122. [CrossRef] [PubMed]

55. Xu, J.-L.; He, J.; Wang, Z.-C.; Wang, K.; Li, W.-J.; Tang, S.K.; Li, S.-P. Rhodococcus qingshengii sp. nov., a carbendazim-degrading bacterium. Int. J. Syst. Evol. Microbiol. 2007, 57, 2754-2757. [CrossRef] 